\title{
Consumo, digestibilidade e balanço de nitrogênio em borregos alimentados com torta de dendê em substituição à silagem de capim-elefante ${ }^{1}$
}

\author{
Lorena da Mota Lima Bringel2 ${ }^{2}$, José Neuman Miranda Neiva ${ }^{3}$, Vera Lúcia de Araújo ${ }^{4}$, Marco \\ Aurélio Delmondes Bomfim ${ }^{5}$, João Restle ${ }^{2}$, Ana Cristina Holanda Ferreira ${ }^{2}$, Raimundo Nonato \\ Braga Lôbo ${ }^{5}$
}

\footnotetext{
1 Pesquisa financiada pelo CNPq.

${ }^{2}$ Curso de Doutorado em Ciência Animal Tropical da Universidade Federal do Tocantins.

${ }^{3}$ Curso de Zootecnia da Universidade Federal do Tocantins - Araguaína,TO.

${ }^{4}$ Curso de Veterinária da Universidade Federal do Tocantins - Araguaína,TO.

${ }^{5}$ Embrapa Caprinos - Sobral, CE.
}

RESUMO - Este trabalho foi realizado com o objetivo de avaliar o consumo voluntário, a digestibilidade aparente e o balanço de nitrogênio em ovinos alimentados com dietas contendo torta de dendê. A adição da torta de dendê foi avaliada nos níveis 0; 20; 40; 60 e 80\% em substituição à silagem de capim-elefante utilizando-se 20 ovinos machos castrados em um delineamento experimental inteiramente casualizado. Em todas as formas como foram expressos, o consumo e a digestibilidade de nutrientes apresentou em geral resposta quadrática aos níveis de torta de dendê utilizados na dieta. A inclusão de torta de dendê nas dietas teve efeito quadrático também sobre o balanço de nitrogênio, que aumentou até o nível de $45 \%$ de adição desse subproduto e decresceu, devido ao baixo consumo de proteína bruta nos maiores níveis. A torta de dendê possui características próprias de um alimento volumoso e tem como principal limitação o baixo consumo alimentar, por isso, seu uso na alimentação de ovinos deve ser restrito ao nível máximo de $37,34 \%$ da dieta total.

Palavras-chave: biocombustíveis, Elaeis guineensis, ruminantes, subproduto, valor nutritivo

\section{Voluntary intake, apparent digestibility and nitrogen balance in sheep fed with palm kernel cake replacing elephant grass silage}

\begin{abstract}
This research was conducted to evaluate the voluntary intake, the apparent digestibility and the nitrogen balance in sheep fed with diets containing palm kernel cake. The addition of palm kernel cake was assessed at the 0 ; 20; 40; 60 and $80 \%$ levels replacing the elephant grass silages by utilizing 20 castrated male sheep in a completely randomized design In all the forms they were expressed, intake and digestibility of nutrients showed quadract effect at the levels of palm kernel pie utilized in the diet. The inclusion of palm kernel pie in the diets had quadract effect also on the nitrogen balance, due to low consumption of crude protein at higher levels. Palm kernel pie presents the characteristics of bulky feed, and its biggest limitation is the low feeding intake, hence, its use at sheep's feeding must be restricted to up to $37.34 \%$ of the total diet.
\end{abstract}

Key Words: biofuel, byproduct, Elaeis guineensis, nutritive value, ruminant

\section{Introdução}

A alimentação corresponde de 30 a $70 \%$ dos custos de produção de ruminantes, dependendo da atividade e do tipo de exploração, o que justifica a busca por alternativas alimentares e de baixo valor comercial, como os resíduos e subprodutos agroindustriais, que representam uma forma de reduzir os gastos com alimentação (Cândido et al., 2008; Miotto et al., 2009; Ferreira et al., 2009; Rego et al., 2010).

Os ruminantes, comparados às demais espécies domésticas, têm grande habilidade em converter subprodutos e resíduos em alimentos nobres (carne e leite) para a população humana, com a utilização de fontes não-convencionais e que não concorrem diretamente com a alimentação humana e de animais monogástricos.

As tortas ou farelos das oleaginosas utilizados para produção de biodiesel no Brasil podem, em sua maioria, ser utilizados na alimentação animal, porém, cada um com suas particularidades quanto aos cuidados no fornecimento aos animais (Abdalla et al., 2008), o que exige mais estudos para o uso racional e em níveis adequados, que não prejudiquem o desempenho produtivo e diminuam os custos.

A expectativa da substituição parcial do óleo diesel por biocombustível de dendê tem sido foco de muitos trabalhos 
e investimentos no Brasil e no mundo, devido à crescente preocupação mundial com o meio ambiente, o que pode aumentar cada vez mais a disponibilidade da torta de dendê, que pode ser inserida na alimentação animal desde que sejam realizadas pesquisas para esclarecimento do perfil nutricional desse subproduto.

A produção brasileira de dendê aumentou de $522.883 \mathrm{t}$ para 1.091.104 t entre 1990 e 2008 (IBGE, 2010) e têm perspectivas de crescimento ainda maiores, tendo em vista a grande área de aptidão para o cultivo dessa espécie, a maior do mundo, a Amazônia brasileira, com 70 milhões de hectares cultiváveis.

Segundo o Compêndio Brasileiro de Alimentação Animal (1998), a torta de dendê é o produto resultante da polpa seca do dendê, após moagem e extração do óleo, e pode conter em sua composição 10\% de umidade, máximo de 22\% de fibra bruta, mínimo de $12 \%$ de proteína bruta, 0,5\% de extrato etéreo, 4\% de matéria mineral e 20 ppb de aflatoxinas.

Este trabalho foi realizado com o objetivo de avaliar o efeito da inclusão de torta de dendê em substituição à silagem de capim-elefante no consumo voluntário, na digestibilidade aparente e no balanço de nitrogênio em dietas para ovinos.

\section{Material e Métodos}

O experimento foi realizado na Escola de Medicina Veterinária e Zootecnia (EMVZ) da Universidade Federal do Tocantins (UFT), no município de Araguaína, localizado na região norte do Tocantins, $07^{\circ} 11^{\prime} 28^{\prime \prime}$ de Latitude Sul e $48^{\circ} 12^{\prime} 26^{\prime \prime}$ de Longitude Oeste.

Foram testados cinco níveis de torta de dendê (Elaeis guineensis, Jacq) (0; 20; 40; 60; 80\%, com base na matéria seca total) em substituição à silagem de capim-elefante (Pennisetum purpureum, Schum) nas dietas experimentais
(Tabelas 1 e 2). O capim-elefante, com 60 dias de brotação, foi cortado manualmente e processado em picadora de forragem convencional regulada para corte em tamanho entre 1 a $2 \mathrm{~cm}$. Como silos experimentais, foram utilizados tambores plásticos de $210 \mathrm{~L}$ nos quais foram colocados $140 \mathrm{~kg}$ de forragem, a fim de atingir a densidade de $666 \mathrm{~kg} / \mathrm{m}^{3}$. Para a vedação dos silos experimentais, foram utilizadas lonas plásticas presas com ligas de borracha.

Para os ensaios de digestibilidade, utilizaram-se 20 borregos machos castrados, sem raça definida, com idade média de 6 meses, peso vivo médio de $24 \mathrm{~kg}$, devidamente vermifugados. Os animais foram alojados em gaiolas metabólicas individuais com acesso para bebedouro, comedouro e cocho para fornecimento de sal mineral

Tabela 1 - Composição da torta de dendê e da silagem de capimelefante

\begin{tabular}{lcc}
\hline Nutriente & \multicolumn{2}{c}{ Ingrediente } \\
\cline { 2 - 3 } & $\begin{array}{c}\text { Torta } \\
\text { de dendê }\end{array}$ & $\begin{array}{c}\text { Silagem de } \\
\text { capim-elefante }\end{array}$ \\
\hline Matéria seca & 91,87 & 19,41 \\
Matéria orgânica & 96,47 & 95,49 \\
Matéria mineral & 3,53 & 4,51 \\
Proteína bruta & 13,97 & 8,14 \\
Extrato etéreo & 10,78 & 2,23 \\
Fibra em detergente neutro & 64,09 & 68,99 \\
Fibra em detergente ácido & 56,02 & 49,90 \\
Hemicelulose & 8,07 & 19,09 \\
Celulose & 30,34 & 43,65 \\
Lignina & 16,56 & 5,44 \\
Proteína insolúvel em detergente & 88,40 & 15,84 \\
neutro (\% PB) & & 13,26 \\
Proteína insolúvel em detergente & 54,11 & 16,12 \\
ácido (\% PB) & & 85,11 \\
Carboidratos não-fibrosos & 7,63 & 75,49 \\
Carboidratos totais & 71,72 & 86,25 \\
Nutrientes digestíveis totais & &
\end{tabular}

PIDN = proteína insolúvel em detergente neutro; PIDA = proteína insolúvel em detergente ácido; $\mathrm{PB}=$ proteína bruta

Tabela 2 - Composição química das dietas experimentais

\begin{tabular}{|c|c|c|c|c|c|}
\hline \multirow[t]{2}{*}{ Variável (\%) } & \multicolumn{5}{|c|}{ \% de torta de dendê nas dietas experimentais } \\
\hline & 0 & 20 & 40 & 60 & 80 \\
\hline Matéria seca & 19,41 & 33,90 & 48,39 & 62,89 & 77,38 \\
\hline Proteína bruta & 8,14 & 9,31 & 10,47 & 11,64 & 12,80 \\
\hline Extrato etéreo & 2,23 & 3,94 & 5,65 & 7,36 & 9,07 \\
\hline Fibra em detergente neutro & 68,99 & 68,01 & 67,03 & 66,05 & 65,07 \\
\hline Celulose & 43,65 & 40,99 & 38,33 & 35,66 & 33,00 \\
\hline Lignina & 5,44 & 7,66 & 9,89 & 12,11 & 14,34 \\
\hline PIDN (\% PB) & 15,84 & 30,36 & 44,86 & 59,38 & 73,89 \\
\hline PIDA (\% PB) & 13,26 & 21,43 & 29,60 & 37,77 & 45,94 \\
\hline Carboidratos não-fibrosos & 16,12 & 14,42 & 12,72 & 11,03 & 9,33 \\
\hline Carboidratos totais & 85,11 & 82,43 & 79,75 & 77,08 & 74,40 \\
\hline
\end{tabular}

PIDN = proteína insolúvel em detergente neutro; PIDA = proteína insolúvel em detergente ácido; PB = proteína bruta. 
ad libitum. Os animais foram distribuídos em delineamento inteiramente casualizado (DIC) com cinco tratamentos (0; 20; 40; 60; 80\% de matéria seca total) e quatro repetições.

O experimento teve duração de 21 dias, com 14 dias de adaptação e 7 dias de coleta de amostras. Durante todo o experimento, o fornecimento dos alimentos foi realizado diariamente, em dois períodos, manhã e tarde, de modo que permitisse aproximadamente $10 \%$ de sobras. Foram coletadas amostras diárias da silagem de capim-elefante e da torta de dendê durante o fornecimento das dietas aos animais e também foram coletadas amostras das sobras. Realizou-se a coleta total de fezes e urina, que foram pesadas e amostradas para posteriores análises laboratoriais. As amostras foram acondicionadas em congelador a $-10^{\circ} \mathrm{C}$ e, ao final do experimento, foram descongeladas, homogeneizadas, présecas a $60^{\circ} \mathrm{C}$ e trituradas em moinho tipo Willey com malha de $1 \mathrm{~mm}$ para posteriores análises bromatológicas. Nos recipientes coletores de urina, foram adicionados $20 \mathrm{~mL}$ de ácido clorídrico 1:1 para evitar perdas de nitrogênio por volatilização.

As análises bromatológicas das amostras (matéria seca, matéria orgânica, matéria mineral, proteína bruta, extrato etéreo, fibra em detergente neutro, fibra em detergente ácido, celulose, hemicelulose, lignina, proteína insolúvel em detergente neutro e proteína insolúvel em detergente ácido), tanto das sobras e fezes quanto de alimento, foram realizadas no Laboratório de Nutrição Animal da Embrapa Caprinos, em Sobral, estado do Ceará, segundo técnicas descritas por Silva \& Queiroz (2002). As amostras com teor de extrato etéreo maior que $9 \%$ foram desengorduradas, segundo metodologia descrita por Mertens (2002), e posteriormente analisadas para determinação dos conteúdos de proteína bruta e fibra em detergente neutro.

Os valores de carboidratos totais (CT) foram obtidos por diferença, de acordo com metodologia descrita por Sniffen et al. (1992), em que CT (\%) $=100-(\% \mathrm{~PB}+\% \mathrm{EE}$ + \%cinzas) e NDT (\%) = PBD $\%+$ FDND $\%+$ CNFD $\%+(2,25$ $\times$ EED\%). Os teores de CNF foram calculados pela diferença entre carboidratos totais e FDN, segundo Hall (2001).

A análise do nitrogênio na urina foi realizada no Laboratório de Nutrição da Universidade Federal do Tocantins (UFT), localizado na Escola de Medicina Veterinária e Zootecnia, Campus Universitário de Araguaína, seguindo as recomendações de Silva \& Queiroz (2002).

Os consumos de nutrientes foram determinados em gramas/dia (g/dia), em porcentagem do peso vivo (\%PV) e em gramas/unidade de tamanho metabólico (g/UTM). A digestibilidade aparente da matéria seca, matéria orgânica, proteína bruta, extrato etéreo, fibra em detergente neutro, fibra em detergente ácido, celulose, hemicelulose, carboidratos não-fibrosos e carboidratos totais foi determinada conforme descrito por Silva \& Leão (1979) e o balanço de nitrogênio, de acordo com metodologia recomendada por Decandia et al. (2000).

Antes da realização das análises estatísticas, foi feito um estudo para verificar se as pressuposições de distribuição normal e homocedasticidade dos dados foram atendidas. As características que não atenderam a essas pressuposições foram transformadas para posteriores análises estatísticas. Os dados obtidos para consumo de extrato etéreo, de proteína insolúvel em detergente neutro e de proteína insolúvel em detergente ácido (g/dia, \%PV, g/UTM), consumo de lignina e de carboidratos não-fibrosos (g/UTM) foram transformados para $\log _{10}$ e o balanço de nitrogênio $(\mathrm{BN})$ foi transformado para $(\mathrm{BN}+10)$ para se proceder à análise de regressão utilizando o programa SAS - Statistical Analyses System.

\section{Resultados e Discussão}

Os consumos de matéria seca, expressos em g/dia, \%PV e g/UTM, apresentaram resposta quadrática $(\mathrm{P}<0,01)$ aos níveis de substituição da silagem de capim-elefante pela torta de dendê nas dietas (Tabela 3).

Os consumos de matéria seca máximos foram verificados nos níveis de substituição de 37,34; 43,00 e 37,88\%, respectivamente, com valores de 875,25 g/dia; 3,63\%PV e 76,71 g/UTM. Quando expresso em \% PV, os valores (3,63\% PV) foram próximos aos sugeridos no NRC (2007) para ovinos de $30 \mathrm{~kg}$ de PV e ganho de peso diário de $200 \mathrm{~g}$. Entretanto, com adição de $80 \%$ de torta de dendê, o consumo de matéria seca foi de apenas $2,3 \%$ do PV, segundo a equação de regressão, inferior ao sugerido pelo NRC (2007) para manutenção de ovinos em crescimento. O consumo de matéria seca pode ser afetado pelo nível de extrato etéreo da dieta e estão envolvidos neste processo os efeitos na fermentação ruminal, na motilidade intestinal, na aceitabilidade dos alimentos, na liberação de hormônios intestinais e na oxidação da gordura no fígado (Allen, 2000).

Neste estudo, os teores de extrato etéreo nas dietas com níveis mais elevados de torta de dendê (60 e 80\% de inclusão) superaram o nível máximo preconizado (5\% da dieta total), uma vez que, a partir deste nível, os lipídeos podem afetar negativamente o consumo de nutrientes, seja por mecanismos regulatórios que controlam o consumo de alimentos, seja pela capacidade limitada dos ruminantes de oxidar os ácidos graxos (Palmquist \& Mattos, 2006). 
Tabela 3 - Consumo de nutrientes em ovinos alimentados com dietas formuladas com torta de dendê em substituição à silagem de capimelefante

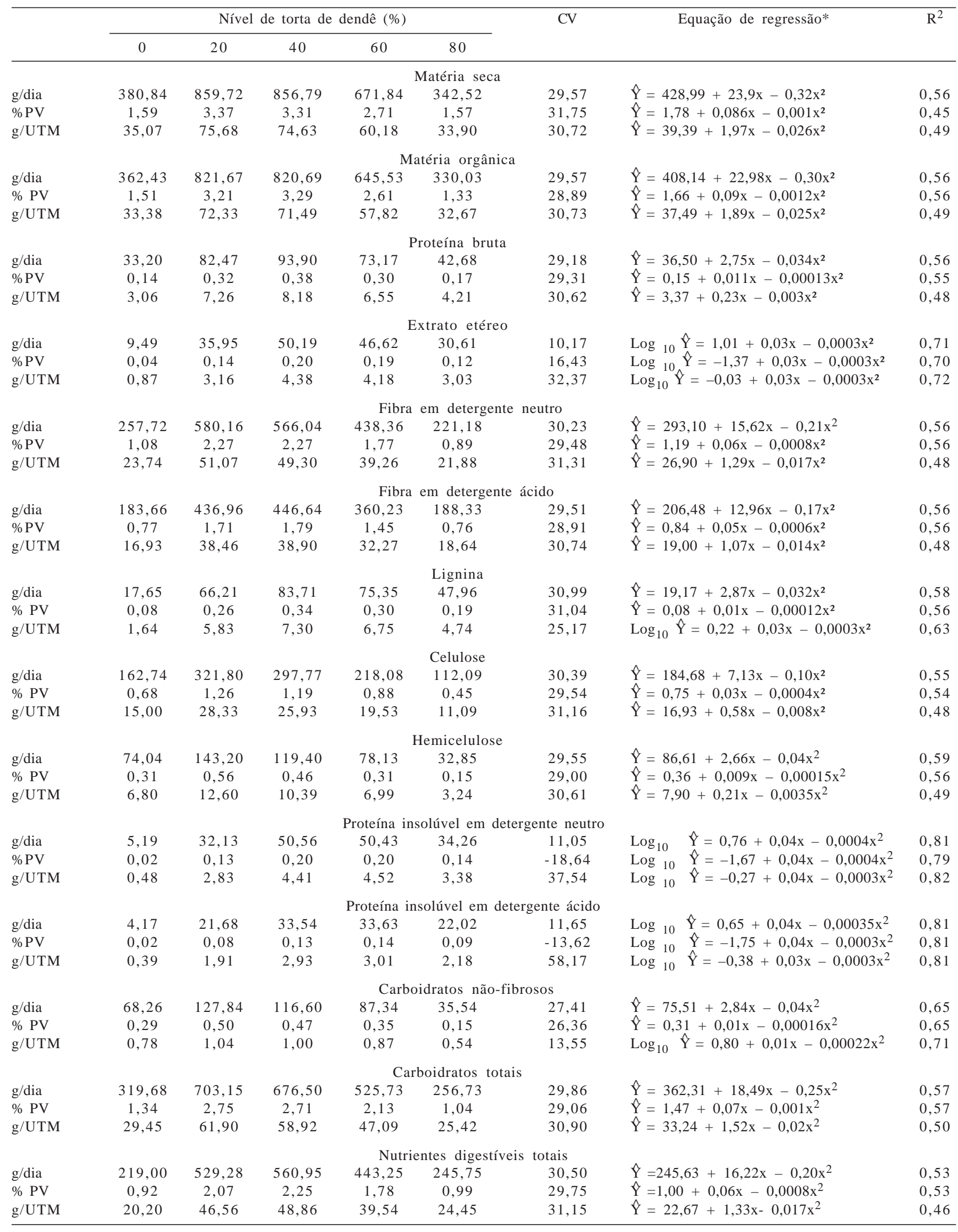

*P<0,01; CV = coeficiente de variação; $\mathrm{R}^{2}$ = coeficiente de determinação. 
Os consumos de matéria seca encontrados em cabras leiteiras por Oliveira Júnior (2000) reduziram linearmente com o aumento nos níveis de grão de soja, fato explicado pelo aumento de extrato etéreo (3,2; 4,4; 5,6 e 6,3\%) na dieta total proveniente da soja em grão. Rodrigues et al.(2003) avaliaram a adição do farelo de castanha de caju ao concentrado de ovinos em terminação e verificaram efeito linear negativo no consumo de matéria seca, quando expresso em g/dia, \%PV e g/UTM. Observaram também que somente a dieta com maior nível de farelo de castanha de caju no concentrado (36\%) foi inferior à dieta controle (0\%), cujo nível de lipídeos ultrapassou o máximo de $6 \%$ da dieta total.

Os efeitos do extrato etéreo no consumo voluntário dependem não somente do nível de lipídeo adicionado, mas também de sua forma física, do tipo de gordura, do conteúdo mineral da dieta e da proporção relativa da fibra na dieta (Zeoula et al., 1995). O óleo de palmiste presente na torta de dendê apresenta, segundo Furlan Júnior et al. (2006), 47,5\% de ácido láurico (12 C) e 16,4\% de ácido mirístico (14 C). Segundo Palmquist \& Mattos (2006), esses ácidos têm natureza anfifílica, isto é, são solúveis tanto em solventes orgânicos como em água, portanto mais tóxicos aos microrganismos ruminais e com maior potencial de inibição de consumo. Assim, o tipo de óleo presente na torta de dendê e o nível de extrato etéreo das dietas podem explicar a redução no consumo de matéria seca nas dietas com torta de dendê em nível maior que 37,34\%.

Silva et al. (2005), estudando a inclusão de torta de dendê e farelo de cacau na alimentação de cabras Saanen, observaram redução do consumo de matéria seca no grupo cuja dieta continha 30\% de farelo de cacau e apontaram como possível causa dessa redução a baixa aceitabilidade do alimento ou a presença de agentes antinutricionais. No entanto, o consumo de matéria seca de dietas contendo 15 e $30 \%$ de torta de dendê não diferenciou $(\mathrm{P}>0,05)$ do observado para a dieta padrão à base de milho e soja, expressos em kg/dia, \%PV e g/UTM.

Rodrigues Filho et al. (1996), avaliando o uso de torta de dendê em substituição ao farelo de trigo em concentrados para ovinos, encontraram valores de consumo voluntário de 55,73; 54,47; 50,72 e 42,98 g/UTM para níveis de 0; 8,9; 17,8 e $29,7 \%$ de torta de dendê, respectivamente, e notaram que, nas mais elevadas proporções de torta de dendê (29,7\%), os consumos foram menores (42,98 g/UTM). Neste mesmo trabalho de Rodrigues Filho et al. (1996), o consumo foi de $864,18 \mathrm{~g} / \mathrm{dia}$, valor superior ao encontrado neste estudo, em que o consumo médio de matéria seca obtido foi de $622,35 \mathrm{~g} /$ dia.

O consumo de matéria orgânica apresentou resposta quadrática $(\mathrm{P}<0,01)$ à substituição da silagem de capim- elefante pela torta de dendê nas dietas (Tabela 3), com valores máximos nos níveis de 38,30; 37,50 e 37,80\% de torta de dendê nas dietas, que correspondem a consumos de 848,21 g/dia; 3,35\%PV e 73,21 g/UTM. O baixo consumo de matéria orgânica nos níveis mais elevados de substituição acompanhou a tendência observada para o consumo de matéria seca e as justificativas para essa ocorrência são idênticas.

O consumo de proteína bruta apresentou resposta quadrática $(\mathrm{P}<0,01)$, em g/dia, \%PV e g/UTM, à substituição da silagem de capim elefante pela torta de dendê nas dietas (Tabela 3). Os consumos máximos de proteína bruta foram encontrados nos níveis de 40,44; 42,31 e 38,33\% de substituição da silagem de capim-elefante pela torta de dendê nas dietas, quando expressos, respectivamente, em g/dia, \%PV e g/UTM. A partir desses níveis, houve redução no consumo de proteína bruta, que acompanhou a queda no consumo de matéria seca a partir do nível de 37,34\% de torta de dendê.

Rodrigues et al. (2003) trabalharam com farelo de castanha de caju no concentrado de ovinos em terminação e observaram redução no consumo de proteína bruta, devido à depressão no consumo de matéria seca quando se incluiu o farelo de castanha de caju à dieta. Valores superiores aos encontrados neste trabalho foram reportados por Silva et al. (2005), que observaram que, entre dietas com 15 e 30\% de torta de dendê no concentrado para cabras leiteiras, o consumo médio foi de 261,19g/dia; 0,53\%PV e 14,03 g/UTM.

Neste estudo, apesar dos altos teores de proteína bruta da torta de dendê, grande parte dessa proteína está complexada à parede celular, o que pode afetar sua disponibilidade aos microrganismos do rúmen. O reduzido consumo de matéria seca pode explicar valores de consumo de proteína bruta inferior a $73 \mathrm{~g} /$ dia nos níveis de substituição acima de $40,44 \%$ de torta de dendê na dieta.

Os consumos de extrato etéreo, expressos em g/dia, \%PV e g/UTM, apresentaram resposta quadrática $(\mathrm{P}<0,01)$ à substituição da silagem de capim-elefante pela torta de dendê nas dietas (Tabela 3), com valores máximos no nível de $50 \%$ de torta de dendê. Os teores de extrato etéreo das dietas aumentaram à medida que a torta de dendê substituiu a silagem de capim-elefante, no entanto, o reduzido consumo de matéria seca nos níveis mais elevados de substituição não permitiu maiores consumos de extrato etéreo nestes níveis.

A substituição da silagem de capim-elefante pela torta de dendê teve efeito quadrático $(\mathrm{P}<0,01)$ sobre os consumos de fibra em detergente neutro, fibra em detergente ácido, hemicelulose, celulose e lignina, quando expressos em g/dia, \%PV e g/UTM (Tabela 3).

O consumo máximo de fibra em detergente neutro foi estimado em 583,56 g/dia, 2,32\%PV e 51,38 g/UTM nos 
níveis de 37,19; 37,50 e 37,94\% de torta de dendê respectivamente. Para o consumo de fibra em detergente ácido, os valores máximos observados foram 453,48 g/dia; 1,89\%PV e 39,45 g/UTM a 38,12; 41,67 e 38,21\% de torta de dendê, respectivamente. Até o nível com $40 \%$ de torta de dendê, houve aumento nos consumos de fibra em detergente neutro, fibra em detergente ácido, celulose e hemicelulose, com decréscimo no consumo de fibra a partir desse nível de substituição, em decorrência da queda no consumo de matéria seca em níveis de substituição acima de 37,34\% de torta de dendê nas dietas experimentais.

Os teores de fibra em detergente neutro das dietas foram relativamente próximos, com teor mínimo no nível de $80 \%$ de torta de dendê $(65,07 \%)$ e máximo nas dietas exclusivas de silagem de capim-elefante (68,99\%). Esses valores são explicados pelo fato de os teores de fibra em detergente neutro da silagem de capim-elefante (68,99\%) serem próximos aos teores de fibra em detergente neutro da torta de dendê (64,09\%). Assim, embora o teor de fibra em detergente neutro (FDN) seja considerado importante fator limitante do consumo de matéria seca, esse princípio parece não se aplicar a este estudo, tendo em vista os teores relativamente próximos de FDN. De acordo com Silva et al. (2005), a inclusão da torta de dendê nas dietas provoca aumento nos teores de fibra em detergente neutro nas dietas de cabras em lactação, entretanto, esse aumento não ocasiona diferença $(\mathrm{P}<0,05)$ em relação aos consumos de FDN obtidos com dietas com 15 e 30\% de torta de dendê no concentrado e com concentrado padrão, à base de milho e farelo de soja.

Os consumos médios diários de proteína insolúvel em detergente neutro (PIDN) e proteína insolúvel em detergente ácido (PIDA) apresentaram resposta quadrática $(\mathrm{P}<0,01)$ à substituição da silagem de capim-elefante pela torta de dendê nas dietas experimentais, quando expressos em g/dia, \%PV e g/UTM (Tabela 3). O consumo máximo de PIDN (g/dia, \%PV e g/UTM) foi verificado nos níveis de 50,0;
50,0 e $66,7 \%$ de torta de dendê, respectivamente, e o de PIDA nos níveis de 57,1; 66,7 e 50,0\% de substituição da silagem de capim-elefante pela torta de dendê nas dietas.

A participação de proteína insolúvel em detergente neutro, proteína complexada à parede celular e por isso de lenta degradação, e proteína insolúvel em detergente ácido, proteína menos disponível e/ou indisponível (ligada à celulose e lignina) aos microrganismos ruminais, aumentou de acordo com os níveis de torta de dendê utilizados na dieta. O teor de lignina quase triplicou nas dietas contendo $80 \%$ de torta de dendê em relação à dieta sem esse subproduto.

O consumo de carboidratos não-fibrosos apresentou resposta quadrática $(\mathrm{P}<0,01)$ aos níveis de substituição da silagem de capim-elefante pela torta de dendê nas dietas (Tabela 5), com valores máximos nos níveis de 35,50; 31,25; 22,73\% de torta de dendê nas dietas. A partir desses níveis, a redução no consumo de carboidratos não-fibrosos se deve ao consumo de matéria seca decorrente da substituição da silagem de capim-elefante pela torta de dendê nas dietas.

Acompanhando o consumo de matéria seca, o consumo de carboidratos totais e nutrientes digestíveis totais apresentou resposta quadrática $(\mathrm{P}<0,01)$ (Tabela 5$)$ aos níveis de substituição da silagem de capim-elefante pela torta de dendê. O consumo de carboidratos totais aumentou até os níveis de 36,98; 35,00 e 38,00\% de substituição da silagem de capimelefante pela torta de dendê, apresentando valor máximo de 704,19 g/dia, 2,70\%PV e 62,12 g/UTM, respectivamente. O consumo de nutrientes digestíveis totais em g/UTM também aumentou até o nível de 39,12\% de torta de dendê.

Rocha Neto (2008), em pesquisa com inclusão do farelo de cacau na alimentação de novilhas leiteiras, observou que os consumos de carboidratos totais e nutrientes digestíveis totais não foram influenciados $(\mathrm{P}>0,05)$ pela adição do subproduto na dieta. Neste estudo, as digestibilidades aparentes da matéria seca, matéria orgânica, proteína bruta

Tabela 4 - Digestibilidade aparente dos nutrientes em ovinos alimentados com dietas contendo torta de dendê em substituição a silagem de capim-elefante

\begin{tabular}{|c|c|c|c|c|c|c|c|c|}
\hline \multirow[t]{2}{*}{ Item, \% } & \multicolumn{5}{|c|}{ Nível de torta de dendê (\%MS) } & \multirow[t]{2}{*}{ CV (\%) } & \multirow[t]{2}{*}{ Equação de regressão } & \multirow[t]{2}{*}{$\mathrm{R}^{2}$} \\
\hline & 0 & 20 & 40 & 60 & 80 & & & \\
\hline Matéria seca & 59,42 & 70,68 & 77,86 & 75,94 & 80,77 & 8,23 & $\hat{Y}=60,42+0,54 x-0,004 x^{2} * *$ & 0,54 \\
\hline Matéria orgânica & 64,14 & 73,42 & 80,28 & 78,46 & 84,95 & 6,62 & $\hat{Y}=65,09+0,43-0,0025 x^{2} * *$ & 0,61 \\
\hline Proteína bruta & 54,11 & 69,98 & 77,15 & 70,52 & 78,89 & 12,90 & $\hat{Y}=56,53+0,64 x-0,005 x^{2} *$ & 0,35 \\
\hline Extrato etéreo & 58,17 & 87,54 & 94,58 & 94,24 & 97,21 & 4,92 & $\hat{Y}=61,54+1,25 x-0,01 x^{2} * *$ & 0,90 \\
\hline Fibra em detergente neutro & 62,95 & 71,34 & 78,40 & 76,01 & 84,50 & 7,47 & $\hat{Y}=64,00+0,36 x-0,0016 x^{2} * *$ & 0,56 \\
\hline Fibra em detergente ácido & 62,69 & 71,11 & 77,75 & 76,49 & 84,71 & 7,22 & $\hat{Y}=63,71+0,35 x-0,0014 x^{2} * *$ & 0,59 \\
\hline Celulose & 72,94 & 75,78 & 81,56 & 78,49 & 86,57 & 5,56 & $\hat{Y}=73,41+0,12 x-0,00033 x^{2} * *$ & 0,44 \\
\hline Hemicelulose & 65,88 & 75,89 & 86,14 & 84,11 & 90,14 & 5,41 & $\hat{Y}=66,28+0,57 x-0,0036 x^{2 * *}$ & 0,77 \\
\hline Carboidratos não-fibrosos & 85,94 & 90,39 & 92,22 & 94,46 & 91,56 & 3,62 & $\hat{Y}=85,77+0,28 x-0,0026 x^{2} *$ & 0,35 \\
\hline Carboidratos totais & 65,40 & 73,10 & 79,65 & 78,15 & 84,50 & 6,44 & $\hat{Y}=66,13+0,36 x-0,0018 x^{2} * *$ & 0,58 \\
\hline
\end{tabular}

$* \mathrm{P}<0,05 * * \mathrm{P}<0,01 . \mathrm{R}^{2}=$ coeficiente de determinação; $\mathrm{CV}=$ coeficiente de variação. 
e extrato etéreo apresentaram resposta quadrática aos níveis de substituição da silagem de capim-elefante pela torta de dendê nas dietas (Tabela 4), pois aumentaram até os níveis de 67,50; 86,00; 64,00 e 62,50\% de torta de dendê, respectivamente, nos quais tenderam a se estabilizar.

A provável causa da queda na digestibilidade da matéria seca das dietas poderia ser os elevados níveis de extrato etéreo na dieta, pois, a partir do nível de inclusão de $40 \%$ de torta de dendê, os teores máximos recomendados (5\% da matéria seca) foram atingidos, o que certamente pode comprometer o aproveitamento do alimento. No entanto, as digestibilidades aparentes da matéria seca, matéria orgânica, proteína bruta e extrato etéreo atingiram valores máximos quando as proporções de torta de dendê foram aproximadamente $60 \%$ superiores ao nível em que se atingiu $5 \%$ de extrato etéreo.

Desse modo, provavelmente a diminuição no consumo de matéria seca a partir de 37,34\% de inclusão de torta de dendê permitiu que houvesse efeito compensatório, pois, com menores consumos há maior aproveitamento do alimento pelos microrganismos ruminais, devido ao provável maior tempo de retenção da digesta no rúmen, ocorrendo melhores digestibilidades dos nutrientes (matéria seca, matéria orgânica, proteína bruta e extrato etéreo) com tendência a se estabilizar a partir do nível com aproximadamente $60 \%$ de torta de dendê nas dietas.

Segundo Van Soest (1994), os teores de nitrogênio insolúvel em detergente ácido dos alimentos interferem na digestibilidade da proteína bruta, o que poderia explicar o comportamento quadrático da digestibilidade da proteína bruta e a redução no seu aproveitamento, devido ao aumento nos teores e no consumo de proteína insolúvel em detergente ácido com a substituição da silagem de capim-elefante pela torta de dendê nas dietas. No entanto, o contrário foi verificado, uma vez que o consumo máximo de proteína insolúvel em detergente ácido foi atingido nos níveis de aproximadamente $50 \%$ de substituição, sendo que o valor máximo de digestibilidade da proteína bruta ocorreu no nível de 64\% de torta de dendê na dieta.

Valores médios de digestibilidade superiores aos deste estudo foram encontrados por Rodrigues Filho et al. (1996), em ovinos, de 81,63; 84,95 e 83,01\% para matéria seca, matéria orgânica e proteína bruta, respectivamente, provavelmente em virtude da melhor qualidade dos alimentos utilizados em associação à torta de dendê. Todavia, quando esses dados foram analisados estatisticamente, não houve diferença na digestibilidades de matéria seca, matéria orgânica e proteína bruta entre os níveis de torta de dendê utilizados em substituição ao farelo de trigo.
Valores de digestibilidade superiores aos encontrados neste estudo, de 72,94; 76,25 e 70,13\%, respectivamente, foram relatados por Souza et al. (2004) em pesquisa com adição de casca de café nas dietas (0,0; 2,5; 5,0; 7,5 e 10,0\% na matéria seca da dieta total). Esses autores observaram que a digestibilidade aparente de matéria seca, matéria orgânica e proteína bruta não se alterou pela adição desse subproduto nas dietas e apresentou valores médios de 60,$1 ; 62,1$ e $66,3 \%$.

As digestibilidades aparentes da fibra em detergente neutro, fibra em detergente ácido, celulose e hemicelulose apresentaram resposta quadrática $(\mathrm{P}<0,01)$ à substituição da silagem de capim-elefante pela torta de dendê nas dietas (Tabela 4). Segundo Van Soest (1994), entre os fatores que podem afetar a digestibilidade, o consumo do alimento tem de grande importância e pode ser afetado pelo grau de moagem, em decorrência da maior velocidade de passagem da digesta pelo trato digestivo. Assim, em sua maioria, o aumento no consumo alimentar ocasiona redução na digestibilidade da fibra.

Seguindo essa hipótese, era de se esperar que, nos níveis com maior concentração de torta de dendê(60 e 80\%), o consumo voluntário fosse maior, devido ao maior grau de moagem (torta de dendê) dessas dietas, no entanto, outros fatores tiveram maior influência (tipo e nível de extrato etéreo) e contribuíram para, provavelmente, reduzir a taxa de passagem da digesta nesses níveis, diminuindo o consumo voluntário e aumentando a digestibilidade da fibra nos níveis de maior concentração de torta de dendê na dieta.

De acordo com Van Soest (1994), o teor de lignina está relacionado negativamente à digestibilidade da fibra. Neste estudo, os teores de lignina aumentaram consideravelmente de $5,44 \%$ no tratamento controle para $14,34 \%$ de lignina no nível com $80 \%$ de torta de dendê, portanto, esperava-se que os maiores teores de lignina nestes níveis prejudicassem a digestibilidade da fibra, o que não ocorreu, visto que a digestibilidade da fibra em detergente ácido e da fibra em detergente neutro alcançou elevados valores nos níveis com maiores quantidades do subproduto.

Sousa (2005), estudando a inclusão de farelo de cacau nos níveis de níveis de 0 a 21\% na dieta de ovinos, não observou diferença $(\mathrm{P}<0,05)$ na digestibilidade da fibra em detergente neutro, que variou de 50,1 a $55,8 \%$, apesar do aumento do nitrogênio insolúvel em detergente neutro com a inclusão do subproduto à dieta. Segundo Carvalho (2006), em ovinos, as digestibilidades aparentes da fibra em detergente neutro e fibra em detergente ácido não se alteram quando há substituição do feno de capim-tifton 85 por torta de dendê na dieta. 
Os valores de digestibilidade dos carboidratos totais ( $\mathrm{P}>0,01)$ e carboidratos não-fibrosos $(\mathrm{P}>0,05)$ apresentaram resposta quadrática à substituição da silagem de capimelefante pela torta de dendê nas dietas, tendenddo a se estabilizar entre os níveis com 40 e $60 \%$ de torta de dendê, devido ao menor consumo de matéria seca nestes níveis, que proporcionou melhor aproveitamento dos alimentos pelos microrganismos ruminais.

Em estudo realizado por Souza et al. (2004), as digestibilidades aparentes de carboidratos totais e carboidratos não-fibrosos em ovinos não se alteraram com a adição de casca de café nas dietas, atingindo valores médios de 61,5 e 84,1\%, respectivamente.

Neste ensaio, a análise de regressão comprovou resposta quadrática $(\mathrm{P}<0,01)$ do balanço de nitrogênio à inclusão da torta de dendêàs dietas (Tabela 5). Verificou-se, assim, balanço de nitrogênio negativo nos animais alimentados com a dieta controle, sem torta de dendê, e isso indica que a exigência de proteína dos animais não foi atendida quando se forneceu somente a silagem de capim-elefante aos animais. Quando a torta de dendê substituiu a silagem de capim-elefante nas dietas, houve balanço de nitrogênio positivo, acompanhando a resposta quadrática do consumo de matéria seca.

O balanço de nitrogênio foi melhor na dieta com até 45\% de torta de dendê e reduziu a partir desse nível devido ao reduzido consumo de proteína bruta a partir do nível com 40,74\% de torta de dendê. Essa redução do nitrogênio ingerido se deve, portanto, à depressão do consumo de matéria seca com a substituição da silagem de capimelefante pela torta de dendê.

Carvalho (2006) encontrou menor retenção de nitrogênio de 1,03 g/dia e 0,06 g/UTM quando forneceu uma dieta contendo $45 \%$ de torta de dendê e atribuíram esse resultado à menor utilização de nitrogênio dietético pelos animais, já que houve menor consumo de nitrogênio nesse grupo. Neste estudo, o aumento da concentração de proteína bruta foi acompanhado pelo maior consumo de nitrogênio até o nível com 40,74\% de torta de dendê. A partir deste nível, o consumo de nitrogênio diminuiu, proporcionando menor retenção de nitrogênio $(\mathrm{BN})$ nos mais elevados níveis de substituição da silagem de capim elefante pela torta de dendê.

Merlo et al. (2008), utilizando farelo de coco em substituição ao feno de capim-tifton 85 , observaram balanço de nitrogênio negativo na dieta com 25\% de inclusão do subproduto, indicando que a dieta foi incapaz de suprir as quantidades adequadas de nitrogênio para ovinos, apesar do seu maior teor de proteína bruta $(9,16 \%)$, logo a redução no consumo, embora não tenha sido significativa, pode ter ocasionado essa condição.

Tabela 5 - Valores médios do nitrogênio ingerido, nitrogênio fecal, nitrogênio excretado na urina e balanço de nitrogênio em função dos níveis de torta de dendê em substituição à silagem de capim elefante nas dietas

\begin{tabular}{|c|c|c|c|c|c|c|c|c|}
\hline \multirow[t]{2}{*}{ Item } & \multicolumn{5}{|c|}{ Nível de torta de dendê (\%MS) } & \multirow[t]{2}{*}{ CV (\%) } & \multirow[t]{2}{*}{ Equação de regressão* } & \multirow[t]{2}{*}{$\mathrm{R}^{2}$} \\
\hline & 0 & 20 & 40 & 60 & 80 & & & \\
\hline N-ingerido & 5,30 & 13,18 & 15,03 & 11,72 & 6,84 & - & - & - \\
\hline $\mathrm{N}$-urina & 3,56 & 4,30 & 3,67 & 4,11 & 4,55 & - & - & - \\
\hline $\mathrm{BN}$ & $-0,56$ & 4,94 & 7,91 & 4,57 & 0,82 & 23,53 & $(\hat{Y}+10)=9,53+0,36 x-0,004 x^{2}$ & 0,42 \\
\hline
\end{tabular}

$\mathrm{CV}=$ coeficiente de variação; $\mathrm{R}^{2}=$ coeficiente de determinação; $\mathrm{N}$-ingerido = nitrogênio consumido, $\mathrm{N}$-fecal = nitrogênio excretado nas fezes; $\mathrm{N}$-urina $=$ nitrogênio excretado na urina; $\mathrm{BN}=$ balanço de nitrogênio.

\section{Conclusões}

A torta de dendê possui características próprias de um alimento volumoso e tem como principal limitação para sua utilização na alimentação de ruminantes, o baixo consumo alimentar, restringindo o seu uso até o nível de inclusão de $37,34 \%$ da dieta total em substituição ao volumoso.

\section{Referências}

ABDALLA, A.L.; SILVA FILHO, J.C.; GODOI, A.R. et al. Utilização de subprodutos da indústria de biodiesel na alimentação de ruminantes. Revista Brasileira de Zootecnia, v.37, p.260-258, 2008 (supl. especial).
ALLEN, M.S. Effects of diet on short-term regulation of feed intake by lactating dairy cattle. Journal of Dairy Science, v.83, n.7, p.1598-1624, 2000.

CÂNDIDO, M.J.D.; BOMFIM, M.A.D.; SEVERINO, L.S. et al. Utilização de co-produtos da mamona na alimentação animal. In: CONGRESSO BRASILEIRO DE MAMONA, 3., 2008, Salvador. Anais... Campina Grande: Embrapa - Algodão, 2008. p.1-21

CARVALHO, E.M. Torta de dendê (Elaeis guineensis, Jacq) em substituição ao feno de capim-tifton 85 (Cynodon spp.) na alimentação de ovinos. 2006. 40f. Dissertação (Mestrado em Zootecnia) - Universidade Estadual do Sudoeste da Bahia, Itapetinga.

COMPÊNDIO BRASILEIRO DE ALIMENTAÇÃO ANIMAL. Brasil. Ministério da Agricultura e Abastecimento. Brasília: Sindicações/Anfar; CBNA; SDR/MA, 1998. 12p.

DECANDIA, M.; SITZIA, M.; CABIDDU, A. et al. The use of polyethylene glycol to reduce the anti-nutritional effects of 
tannins in goat fed woody species. Small Ruminant Research, v.38, n.2, p.157-164, 2000.

FERREIRA, A.C.H.; RODRIGUEZ, N.M.; NEIVA, J.N.M. et al. Desempenho produtivo de ovinos alimentados com silagens de capim-elefante contendo subprodutos do processamento de frutas. Revista Ciência Agronômica, v.40, p.315-322, 2009.

FURLAN JÚNIOR, J.; KALTNER, F.J.; AZEVEDO, G.F.P. et al. Biodiesel: Porque tem que ser dendê. Belém: Embrapa Amazônia Oriental, Palmasa, 2006. 205p.

HALL, M.B. Recent advanced in non-ndf carbohydrates for the nutrition of lactating cows. In: SIMPÓSIO INTERNACIONAL EM BOVINOS DE LEITE: Novos conceitos em nutrição, 2., 2001, Lavras. Anais... Lavras: Universidade Federal de Lavras, 2001. p.139-148.

INSTITUTO BRASILEIRO DE GEOGRAFIA E ESTATÍSTICA IBGE. Produção agrícola municipal (PAM). [2010]. Disponível em: <http://www. sidra.ibge.gov.br>. Acesso em: 10 jul. 2010.

MERLO, F.A.; SILVA, A.M.G.M.; BORGES, I. et al. [2008]. Valor nutritivo do farelo de coco em ovinos - balanço energético e de nitrogênio. Disponível em: <http://www.repdigital.cnptia. embrapa.br/handle/CPATSA/37415> Acesso em: 2 abr. 2011.

MERLO, F.A.; SILVA, A.M.G.M.; BORGES, I. et al. Valor nutritivo do farelo de coco em ovinos - balanço energético e de nitrogênio. In: SIMPÓSIO INTERNACIONAL SOBRE CAPRINOS E OVINOS DE CORTE, 2007, João Pessoa. Anais... João Pessoa: EMEPA, 2007. v.3. p.1-5.

MERTENS. Gravimetric determination of amylase - treated neutral detergent fiber in feeds with refluxing in beakers or crucibles collaborative study. Journal of AOAC International, v.85, n.6, p.1217-1240, 2002.

MIOTTO, F.R.C.; NEIVA, J.N.M.; VOLTOLINI, T.V.J. et al. Desempenho produtivo de tourinhos Nelore $\mathrm{x}$ Limousin alimentados com dietas contendo gérmen de milho integral. Revista Ciência Agronômica, v.40, p.624-632, 2009.

NATIONAL RESEARCH COUNCIL - NRC. Nutrient requirements of small ruminants. Washington, D.C.: National Academy Press, 2007. 362p.

OLIVEIRA JÚNIOR, R.C.; SUSIN, U.; PIRES, A.V. et al. Efeito de níveis de grãos soja na dieta de cabras: 2 Produção e composição do leite. In: REUNIÃO ANUAL DA SOCIEDADE BRASILEIRA DE ZOOTECNIA, 37., 2000. Viçosa, MG. Anais... Viçosa, MG: Sociedade Brasileira de Zootecnia, [2000]. (CD-ROM).
PALMQUIST, D.L.; MATTOS, W.R.S. Metabolismo de lipídeos. In: BERCHIELLI, T.T.; PIRES, A.V.; OLIVEIRA, S.G. (Eds.) Nutrição de ruminantes. Jaboticabal: Funep, 2006. p.287-310.

REGO, M.M.T.; NEIVA, J.N.M.; REGO, A.C. et al. Intake, nutrients digestibility and nitrogen balance of elephant grass silages with mango by-product addition. Revista Brasileira de Zootecnia, v.39, p.74-80, 2010.

ROCHA NETO A.L. Farelo de cacau na dieta de novilhas leiteiras. 2008. 65f. Dissertação (Mestrado em Zootecnia) Universidade Estadual do Sudoeste da Bahia, Itapetinga.

RODRIGUES FILHO, J.A.; CAMARÃO, A.P.; BATISTA, H.A.M. et al. Níveis de torta de dendê em substituição ao farelo de trigo no consumo voluntário e digestibilidade de concentrados. In: REUNIÃO DA SOCIEDADE BRASILEIRA DE ZOOTECNIA, 35., 1996, Fortaleza. Anais... Fortaleza. 1996. p.292-293.

RODRIGUES; M.M.; NEIVA, J.N.M.; VASCONCELOS, V.R. et al. Utilização do farelo de castanha de caju na terminação de ovinos em confinamento. Revista Brasileira de Zootecnia, v.32, n.1, p.240-248, 2003.

SILVA, D.J.; QUEIROZ, A.C. Análise de alimentos: métodos químicos e biológicos. 3.ed. Viçosa, MG: Editora UFV, 2002. 235p.

SILVA, J.F.C; LEÃO, M.I. Fundamentos da nutrição dos ruminantes. Piracicaba: Livroceres, 1979. 384p.

SILVA, H.G.O.; PIRES, A.J.V.; SILVA, F.F. et al. Farelo de cacau (Theobroma cacao L.) e torta de dendê (Elaeis guineensis, Jacq) na alimentação de cabras em lactação: consumo e produção de leite. Revista Brasileira de Zootecnia, v.34, n.5, p.1786-1794, 2005.

SNIFFEN, C.J.; O'CONNOR, J.D.; VAN SOEST, P.J. et al. A net carbohydrate and protein system for evaluating cattle diets: II. Carbohydrate and protein availability. Journal of Animal Science, v.70, n.11, p.3562-3577, 1992.

SOUSA, F.G. Níveis crescentes de farelo de cacau (Theobroma cacao L.) na alimentação de ovinos. 2005. 58f. Dissertação (Mestrado em Agronomia) - Universidade Estadual do Sudoeste da Bahia, Vitória da Conquista.

SOUZA, A.L.; GARCIA, R.; BERNADINO, F.S. et al. Casca de café em dietas de carneiros: consumo e digestibilidade. Revista Brasileira de Zootecnia, v.33, n.6, p.2170-2176, 2004.

VAN SOEST, P.J. Nutritional ecology of the ruminant. Cornell University. 2.ed. p.476, 1994.

ZEOULA, L.M.; BRANCO, A.F.; PRADO, I.N. et al. Consumo voluntário e digestibilidade aparente do caroço integral de algodão e bagaço hidrolisado de cana-de-açúcar para ruminantes. Revista Brasileira de Zootecnia, v.24, n.1, 1995. 